The Canadian Journal of

Chemical Engineering

\title{
From Molecules to Processes: Molecular Simulations Applied to the Design of Simulated Moving Bed for Ethane/Ethylene Separation
}

\begin{tabular}{|c|c|}
\hline Journal: & The Canadian Journal of Chemical Engineering \\
\hline Manuscript ID: & CJCE-12-0551.R1 \\
\hline Wiley - Manuscript type: & Article \\
\hline Date Submitted by the Author: & $\mathrm{n} / \mathrm{a}$ \\
\hline Complete List of Authors: & $\begin{array}{l}\text { Granato, Miguel; Faculdade de Engenharia da Universidade do Porto, LSRE } \\
\text { - Laboratory of Separation and Reaction Engineering - Associate } \\
\text { Laboratory LSRE/LCM } \\
\text { Martins, Vanessa; Faculdade de Engenharia da Universidade do Porto, } \\
\text { LSRE - Laboratory of Separation and Reaction Engineering - Associate } \\
\text { Laboratory LSRE/LCM } \\
\text { Santos, João; Faculdade de Engenharia da Universidade do Porto, LSRE - } \\
\text { Laboratory of Separation and Reaction Engineering - Associate Laboratory } \\
\text { LSRE/LCM } \\
\text { Jorge, Miguel; Faculdade de Engenharia da Universidade do Porto, LSRE - } \\
\text { Laboratory of Separation and Reaction Engineering - Associate Laboratory } \\
\text { LSRE/LCM } \\
\text { Rodrigues, Alírio; Faculdade de Engenharia da Universidade do Porto, LSRE } \\
\text { - Laboratory of Separation and Reaction Engineering - Associate } \\
\text { Laboratory LSRE/LCM }\end{array}$ \\
\hline Keywords: & $\begin{array}{l}\text { Zeolite } 13 X \text {, Ethane/Ethylene, Simulated Moving Bed, Molecular } \\
\text { Simulation, Monte Carlo }\end{array}$ \\
\hline
\end{tabular}




\title{
From Molecules to Processes: Molecular Simulations Applied
} to the Design of Simulated Moving Bed for Ethane/Ethylene

\section{Separation}

\author{
Miguel Angelo Granato $^{\S^{*}}$, Vanessa Duarte Martins ${ }^{\S}$,João Carlos Santos ${ }^{\S}$ \\ Miguel Jorge ${ }^{\S}$, and Alírio Egídio Rodrigues ${ }^{\S}$ \\ ${ }^{\S}$ LSRE - Laboratory of Separation and Reaction Engineering - Associate Laboratory \\ LSRE/LCM, Faculdade de Engenharia, Universidade do Porto, Rua Dr. Roberto Frias. \\ 4200-465 - Porto, Portugal \\ * To whom correspondence should be addressed: Phone +351 22508 1578; Fax: +351 \\ 22508 1674. E-mail: mgranato@fe.up.pt
}

\begin{abstract}
This paper presents results of a modelling study on the separation of ethane/ethylene mixture by selective adsorption on zeolite $13 \mathrm{X}$ in a Simulated Moving Bed (SMB) unit. Propane and $n$-butane are evaluated as desorbent candidates. The study encompasses molecular simulation calculations for determination of adsorption parameters, whose results will then be used in a mathematical model for evaluating the performance of an SMB unit. This work is entirely done in silico, by using available force field parameters for the molecular simulations part, and reliable mathematical models for the SMB part. Experimental data are solely used for comparison with the molecular simulation results, which are subsequently expanded to calculate adsorption properties for separating the mixtures, without further experimental work. The separation regions of an SMB unit operating with zeolite $13 \mathrm{X}$ for ethane/ethylene separation, using propane and $n$-butane
\end{abstract}


as desorbents, were obtained by simulation at $110 \mathrm{kPa}$ and at four different temperatures: 298, 323, 348 and 373 K. For each desorbent, an operating point was selected and the size of the required unit was presented for the complete separation of the two components of the mixture.

\section{Keywords}

Zeolite 13X; Ethane; Ethylene; Simulated Moving Bed; Molecular Simulation; Monte Carlo

\section{Introduction}

Ethylene (ethene) is the major worldwide industrial feedstock, one of the most important raw materials for the chemical industry with an annual production of more than 25 million tons in the United States (Kirk-Othmer, 1991). Separation of paraffin/olefin mixtures, in particular ethane/ethylene and propane/propylene, requires huge distillation columns operated at a very high reflux ratio, one of the most energy consuming processes in the chemical industry (Rege et al., 1998). Alternative technologies are Simulated Moving Bed (SMB) and Vacuum Swing Adsorption (VSA). The Simulated Moving Bed (SMB) technology comes from the early 1960's, with its first important industrial implementation of the Sorbex process by UOP. Since then, it has been successfully applied, first to various large petrochemical separations, including $p$-xylene separation from its $\mathrm{C} 8$ isomers, olefin/paraffin separation, and more recently in the pharmaceutical and fine chemical industries (Sá Gomes et al., 2008). The Sorbex process operates mostly in the liquid phase by employing two separating agents: the eluent (or desorbent) and the adsorbent. The eluent can either be a gas or a liquid. The extract and the raffinate (products) are diluted with the eluent and additional separation steps, by flash or fractional distillation, are required to yield the pure products. 
However, the Sorbex process can also be used for gas phase separations where a vapour or a supercritical fluid, typically $\mathrm{CO}_{2}$, is used as eluent. Mazzotti and co-workers developed a six-port vapour phase SMB pilot plant for the separation of an $n$-pentane/iso-pentane mixture using $n$-heptane as desorbent and 5A-Zeolite as adsorbent. They reported a higher separation efficiency in a vapour-phase SMB unit compared to the liquid phase separation (Mazzotti et al., 1995). Relevant references to the SMB application in the separation of propylene/propane mixtures are found in the literature (Rao et al., 2005; Cheng and Wilson, 2001). Rao and collaborators reported results for this separation using silica gel as adsorbent in a moving-port system which, when embedded into a fixed bed, facilitates the continuous movement of the port along the bed for the injection and withdrawal of a fluid. The parametric study indicates that high purity products and a higher productivity by an order of magnitude can be achieved with simulated moving-beds compared to the fixed beds (Rao et al., 2005).

In considering the ethane/ethylene separation by $\mathrm{SMB}$, a suitable desorbent is a fundamental issue. The choice of an adequate desorbent for the separation of ethane/ethylene by gas phase SMB should consider the subsequent distillation step in order to concentrate the extract/raffinate, and to recover the desorbent. The difference between the boiling point of the desorbent and that of the raffinate (or the extract), and the presence or not of azeotropes are of key importance for the efficiency of the distillation. Propane and $n$-butane are proposed as candidate desorbents for separation of the ethane/ethylene mixture, and this is tested using predictive simulations with little input from experiment. At $101.3 \mathrm{kPa}(1 \mathrm{~atm})$, ethane has a boiling point of $-89^{\circ} \mathrm{C}$, and ethylene has one of $-103.7^{\circ} \mathrm{C}$. The boiling point of $n$-butane is $-0.5{ }^{\circ} \mathrm{C}$ and that of propane is $-42.1^{\circ} \mathrm{C}$, and thus both desorbents would be adequate for further separation by distillation. 
Normally the choice of desorbent is made by trial-and-error, requiring expensive and time-consuming experimental measurements of adsorption equilibrium. A much more efficient alternative would be to choose the desorbent based on computational simulations of the SMB process, minimizing the need for experiments. However, this requires a simulation approach that can accurately predict multi-component adsorption equilibrium in the adsorbent material, and then feed this data into a large-scale simulation of the process - in other words, a simulation approach that goes from molecules to processes.

In this study, we attempt to achieve this goal by combining molecular simulation of adsorption with process simulations. Single component adsorption isotherms of all the four species herein studied, as well as binary mixtures of ethane/ethylene, ethane/propane, ethylene/propane, ethane/ $n$-butane, and ethylene $/ n$-butane in zeolite $13 \mathrm{X}$ were calculated by the configurational-bias Monte Carlo (CBMC) technique. Molecular simulations are the first prediction tool to be used here, aiming to replace expensive, time consuming and, in some cases, dangerous experiments. We adopted force fields that have been widely used to predict adsorption of hydrocarbons in zeolites (Calero et al., 2004, Lamia et al., 2009, Granato et al., 2010), and use them to reproduce experimental data on single component adsorption of ethane and ethylene in $13 \mathrm{X}$ zeolite, as well as their binary mixtures with propane and $n$-butane. Subsequently, a four-section Simulated Moving Bed (SMB) unit is analyzed through simulation, in order to describe the behaviour of the unit by means of a mathematical model. This model makes use of the equilibrium adsorption data, predicted by molecular simulation, in a wide range of operating conditions. We demonstrate that this integrated approach is a powerful tool for computational design of adsorptive separation processes. 


\section{Computational Details}

\section{1 - Molecular Simulation Methods}

The configurational-bias Monte Carlo (CBMC) technique in the grand-canonical $(\mu V T)$ ensemble has been extensively applied for calculation of adsorption properties, such as isotherms and heats of sorption. This technique allows for accurate calculations of the adsorbed amount, since it allows the total number of molecules to vary by way of creation and deletion Monte Carlo trials. A detailed explanation of this simulation technique can be found elsewhere (Vlugt et al., 1999; Smit and Krishna, 2001; Frenkel and Smit, 2002). For simple hydrocarbons, such as alkanes or alkenes, a number of $2 \times$ $10^{6}$ cycles is enough to reach equilibrium. The United Atom (UA) force field was chosen to model the adsorbates due to a good compromise between accuracy and computational effort, when compared to the All Atom (AA) or the Anisotropic United Atom (AUA) force fields. These models are widely described in the literature (Martin and Siepmann, 1998; Ungerer et al., 2000). For calculations of adsorption properties, such as isotherms and heats of sorption, the UA model is advantageous because of its reduced set of parameters to represent the inter- and intra-molecular interactions between the pseudo-atoms.

The 13X zeolite framework model is the sodium form of the Faujasite (FAU) type zeolite, obtained by randomly replacing silicon by aluminium, satisfying the Löwenstein rule. This substitution generates a negatively charged framework which is compensated by inserting 88 sodium cations, yielding a composition of $\mathrm{Na}_{88} \mathrm{Al}_{88} \mathrm{Si}_{104} \mathrm{O}_{384}$ per unit cell. The cations are allowed to move inside the zeolite. Periodic boundary conditions were applied in all directions. A rigid structure was 
considered for the zeolite, since framework flexibility has little influence on adsorption properties in zeolites (Vlugt and Schenk, 2002).

Non-bonded interactions are described by Lennard-Jones potentials, as shown in Equation 1. A truncated and shifted potential is applied $\left(r_{c u t}=12 \AA\right)$, and tail corrections are not used (Dubbeldam et al., 2004). Electrostatic interactions are calculated by the Ewald summation which is largely described elsewhere (Frenkel and Smit, 2002; Martin and Siepmann, 1998).

$$
U\left(r_{i j}\right)= \begin{cases}4 \varepsilon_{i j}\left[\left(\frac{\sigma_{i j}}{r_{i j}}\right)^{12}-\left(\frac{\sigma_{i j}}{r_{i j}}\right)^{6}\right] & r_{i j} \leq r_{c u t} \\ 0 & r_{i j}>r_{c u t}\end{cases}
$$

Equation 2 describes the Lorentz-Berthelot mixing rules, used to calculate the cross interactions between different united atoms, except for the interactions with the nonframework cations, which requires specific parameters (Vlugt, 2000).

$$
\sigma_{i j}=\frac{1}{2}\left(\sigma_{i i}+\sigma_{j j}\right), \quad \varepsilon_{i j}=\sqrt{\varepsilon_{i i} \varepsilon_{j j}}
$$

All adsorbate molecules were considered to be flexible, with intramolecular parameters taken from the TraPPE force-field (Martin and Siepmann, 1998). Parameters for the interactions between adsorbates and the framework were taken from our previous modelling work of propane/propylene adsorption on zeolite 13X (Granato et al., 2007), which consisted of a modification of the original model by Calero et al. (2004). All molecular interaction parameters are given in Tables S1 and S2 of the Supporting Information File. 


\section{2 - SMB Process Simulations}

Detailed descriptions of the gas phase SMB operation, the mathematical models, and required parameters can be found in the literature (Cheng and Wilson, 2001; Minceva et al., 2003; Leão and Rodrigues, 2004; Sá Gomes et al., 2008, 2009; Lamia et al., 2009). In this study, a "classical" SMB mode of operation, making use of a desorbent species, as patented by Rodrigues et al. (2006), was chosen for the separation of a mixture of ethane-ethylene over $13 \mathrm{X}$ zeolite. In the mathematical model of the four-section SMB unit, a multicomponent extension of the Toth isotherm and a linear driving force (LDF) for the intra-particle mass transfer are assumed. The mathematical model further assumes plug flow with axial dispersion, no radial gradients inside the column, bed void fraction, radius and porosity of the particles are constant along the axial coordinate, negligible thermal effects, negligible pressure drop and fast rate of adsorption. The isothermal assumption for gas-phase SMB was tested by Sá Gomes et al. (2009) in the study of propane/propylene separation, and a temperature gradient of $4 \mathrm{~K}$ was observed along the entire unit. More details can be found elsewhere (Cruz et al., 2005; Minceva et al., 2003; Leão and Rodrigues, 2004). The simulation of an SMB unit may be performed by two methods: the True Moving Bed (TMB), and the SMB approach. Both TMB and SMB model predictions of steady-state performance of the SMB unit are very close. So, the TMB model was selected to study the feasibility of this separation at different temperatures, and using the proposed desorbents - propane and $n$-butane. The Separation Volume methodology (Azevedo and Rodrigues, 1999) was used to find the operating conditions of the SMB unit. 


\section{Results and Discussion}

\subsection{Ethane, Ethylene, Propane and $n$-Butane Single Component} Adsorption in Zeolite 13X

Single component isotherms of ethane and ethylene adsorption in zeolite $13 \mathrm{X}$ were simulated at temperatures of 305,393 and $423 \mathrm{~K}$, and pressure ranges from 1 to 200 $\mathrm{kPa}$. There are many experimental studies on adsorption of ethane and ethylene over Na-Faujasites in the literature (Danner and Choi, 1978; Kaul, 1987; Dunne et al. 1996; Valezuela and Myers, 1989). Danner and Choi (1978) evaluated prediction models of adsorption equilibria of binary mixtures of ethane/ethylene on $13 \mathrm{X}$ pellets containing $20 \%$ by weight of inert clay binder and $80 \%$ percent synthetic zeolite; Dunne and coworkers made simultaneous measurements of isosteric heats of adsorption and adsorption isotherms of a series of gases, including $\mathrm{C}_{2} \mathrm{H}_{6}$, on adsorbents of varying pore structure and ion type (NaX, H-ZSM-5, Na-ZSM-5).

Figures 1 (a) and (b) show equilibrium adsorption isotherms of ethane and ethylene over zeolite $13 \mathrm{X}$ compared with experimental results. The shape of the isotherms is well reproduced, and there is good agreement between simulation results and the experimental data for pure gases. The slight differences between our simulations and experiments from Kaul (1987) are probably due to the use in experiments of pelletized zeolite that can present structural imperfections, pore blocking, surface adsorption, and inactivation of part of the zeolite. On the contrary, the simulations assume a perfect zeolite crystal, which can cause some differences between simulation results and experimental data. So, we also performed simulations of ethane at $305 \mathrm{~K}$ for comparison with experiments carried out with a commercial sample of $\mathrm{NaX}$ powder 
(Dunne et al. 1996). Figure 2 shows an excellent agreement between simulations and experiments.

Equilibrium adsorption isotherms of propane and $n$-butane in zeolite $13 \mathrm{X}$ are equally well reproduced by our model, as shown in previous work (Granato et al., 2007, 2010). For completeness, the comparison between experiment and simulation for propane and $n$-butane are given in the Supporting Information. It should be noted that the ethane/ethylene data were verified with experimental measurements up to $200 \mathrm{kPa}$, while $n$-butane/propane has been validated with experimental data measured up to $\sim 110$ $\mathrm{kPa}$.

\subsection{Adsorption of Binary Mixtures in Zeolite 13X}

The good agreement obtained for pure-component adsorption gives us confidence to use our simulations for multi-component adsorption predictions. Nevertheless, we further validate our models by simulating binary adsorption equilibrium and comparing to results estimated from experimental single-component data using the multicomponent extended Toth model (Valezuela and Myers, 1989). The experimental single component adsorption equilibrium data for ethane and ethylene on $13 \mathrm{X}$ presented by Danner and Choi (1978) at $298 \mathrm{~K}$ and $323 \mathrm{~K}$ were fit with the Toth equation, described by equation 3:

$$
q_{i}=q_{s, i} \frac{b_{i} P_{i}}{\left(1+\left(b_{i} P_{i}\right)^{t_{i}}\right)^{1 / t_{i}}}
$$

where $q_{i}$ represents the concentration of component $i$ in the adsorbed phase, $q_{s}$ is the saturation capacity, $P_{i}$ is the partial pressure of component $i, t_{i}$ is a parameter of the model that characterizes the system heterogeneity and $b$ is the affinity constant that depends on the temperature, $T$, as follows: 


$$
b_{i}=b_{0, i} e^{\frac{-\Delta H_{i}}{R T}}
$$

where $b_{0}$ is the affinity constant at infinite temperature, $\Delta H$ is the isosteric heat of adsorption at zero loading and $R$ is the universal gas constant. The parameters of the fit obtained are presented in Table 1. This table also presents the parameters of the Toth equation for propane taken from Da Silva and Rodrigues (1999), and the parameters for $n$-butane obtained from a fit to the experimental data presented by Tarek et al. (1995).

Da Silva and Rodrigues (1999) determined the adsorption isotherm data of propane from 303 to $473 \mathrm{~K}$ and up to $110 \mathrm{kPa}$. Tarek et al. (1995) determined the adsorption isotherm data of $n$-butane from 300 to $360 \mathrm{~K}$ and up to 150 Torr $(\sim 20 \mathrm{kPa})$. The temperatures used in the SMB simulations are within the range studied by these authors. The maximum pressure used in the adsorption measurements for $n$-butane was high enough to obtain the saturation capacity. Da Silva and Rodrigues used pellets of $13 \mathrm{X}$ while Tarek et al. (1995) used powder. In a real unit, a shaped 13X would have to be used to avoid large pressure drops. Therefore the saturation capacity presented by Tarek et al. (1995) was reduced by $20 \%$ to represent the mass fraction of binder and to level with the data presented by Da Silva and Rodrigues (1999) and by Danner and Choi (1978) for ethane and ethylene.

The multicomponent extension of the Toth equation is described by:

$$
q_{i}=q_{s, i} \frac{b_{i} P_{i}}{\left(1+\left(\sum_{j=1}^{n c} b_{j} P_{j}\right)^{t_{i}}\right)^{1 / t_{i}}}
$$

The prediction of the multicomponent adsorption equilibrium obtained with this fit was compared with the binary data obtained by CBMC simulations. Excellent agreement was observed for all conditions tested. As an example, the comparison for ethane/ethylene binary adsorption equilibrium data at $323 \mathrm{~K}$ and a total pressure of 137.8 
$\mathrm{kPa}$ is presented in Figure 3. Results from binary adsorption experiments reported by Kaul (1987) are also included in this figure, and remarkable agreement between simulation and experiment is observed.

Additional CBMC simulations for the binary adsorption equilibria of propane and $n$-butane with ethane and ethylene, respectively, have been carried out at $373 \mathrm{~K}$ and several molar fractions. The simulation results are compared with data provided by the extended Toth model (Valezuela and Myers, 1989) for propane/ethane, propane/ethylene, $n$-butane/ethane, and $n$-butane/ethylene systems, using the data from pure component adsorption isotherms. The resulting $\mathrm{x}-\mathrm{y}$ diagrams are shown in Figures $4 \mathrm{a}$ and $4 \mathrm{~b}$. The set of force field parameters successfully reproduce the equilibrium adsorption properties of the binary mixtures propane and $n$-butane with ethylene and ethane.

\section{3 - Simulated Moving Bed Simulations}

The next step in our multiscale modelling strategy is to use molecular simulation data, presented in the previous sections, directly as input into the SMB model. The separation regions of the gas phase simulating moving bed (SMB) were obtained by simulation and are presented in Figures 5 and 6. The gammas represent the ratio between the fluid velocity, $v_{j}$, in the respective section and the solid velocity, $u_{s}$, as described by

$$
\gamma_{j}=\frac{v_{j}}{u_{s}}
$$

where $j$ is the SMB section (I, II, III, IV).

Table 2 presents the model parameters chosen to obtain the separation region. The properties of the adsorbent were taken from Da Silva and Rodrigues (1999). It should be noted that the separation region does not depend on the values of gamma 1 and gamma 4 as long as they are large enough and small enough, respectively, to ensure that 
sections I and IV are cleaned. Furthermore, the advantage of representing the separation region in terms of the dimensionless variables gamma 2 and gamma 3 is that these results do not depend on the size of the columns (unless there is a strong mass transfer resistance, which is not the case here). This means that a point can be chosen from the separation region and we can either obtain the size of a unit for a given feed flow rate or obtain the feed flow rate for a given size.

Figure 7 shows the adsorption capacity of the four species at 298, 323, 373 and 423 $\mathrm{K}$, obtained from the parameters presented in Table 1. Propane has an intermediate adsorption capacity, which is a desired property for a desorbent in a simulated moving bed process. Ethylene is the species with the highest adsorption capacity; therefore, a mixture of ethylene and propane will be obtained in the extract of the SMB. Ethane, as the least adsorbed species, will be obtained in the raffinate together with propane. However, $n$-butane has a strong interaction with the adsorbent, which means that it will hardly be displaced by the other species. It has a lower saturation capacity (crosses the other isotherms at a pressure bellow $100 \mathrm{kPa}$ ) which, depending on the temperature and feed composition, may not be able to displace the other two adsorbates.

It is worth mentioning that at $323 \mathrm{~K}$ the equilibrium adsorption isotherm of propane is between the ones of ethane and ethylene while at $373 \mathrm{~K}$, the propane isotherm crosses the ethylene adsorption isotherm at around $40 \mathrm{kPa}$.

The separation region for a feed of $80 \%$ ethylene and $20 \%$ ethane at $110 \mathrm{kPa}$ and 298 , 323,348 and $373 \mathrm{~K}$, using $13 \mathrm{X}$ as adsorbent and propane as desorbent, and a switching time of $76.5 \mathrm{~s}$ is presented in Figure 5. The separation region for the case where $n$-butane is used as desorbent is presented in Figure 6. These regions represent the production of both ethane and ethylene with purities above 99.5\%. As mentioned by Gleich (US Patent 3921411 - 1975), the composition of the feed of a C2-splitter can widely change 
upon the choice of the feedstock and of the sequence selected upstream the splitter. Typical feed compositions have an ethane/ethylene ratio from about 1:3 to $3: 1$. The feed composition chosen in this work is similar to the one presented in Example II of that patent.

As it can be seen from the simulation results, the separation is feasible. When propane is used as desorbent it can be clearly observed that the separation region increases with the decrease of the temperature. This is due to the increase of the adsorption capacity (as shown in Figure 7), and to the increase of the selectivity. Figure 8 presents the adsorption capacity of different mixtures of ethane/ethylene at a total pressure of 110 $\mathrm{kPa}$ and at 323 and $373 \mathrm{~K}$ obtained from the parameters presented in Table 1 and with Equation 5. As it can be seen, the increase of the temperature decreases the selectivity of the adsorbent towards each species. As mentioned before, this decrease of the selectivity decreases the separation region. When $n$-butane is used at desorbent this effect of the selectivity in the separation region is not so clear. This is due to the strong interaction of $n$-butane with the adsorbent, which makes it hard to be displaced by ethane and by ethylene.

Additionally, the heights of the "triangle" that represents the separation region are much smaller when $n$-butane is used. This indicates a smaller productivity when using this desorbent. The dimensionless velocity in zone IV, however, is much smaller when $n$-butane is used. For the same time switch this is translated in a lower flow rate of the recycle pump and thus, in a smaller energy consumption of the SMB unit. However, the overall energy consumption, i.e., the energy consumption of the SMB and the energy consumption of the units to separate ethane and ethylene from the desorbent, rather than the energy consumption of the SMB unit alone, is the one that must be taken into account. 
Although the separation region at $298 \mathrm{~K}$ when using propane as desorbent is the largest, from an industrial point of view, the operation at $323 \mathrm{~K}$ is more favourable. Additionally, economical aspects should be taken into consideration for selecting the best operating temperature. At $298 \mathrm{~K}$ the adsorption isotherms of ethane and ethylene are very steep (see Figure 7). As a consequence, the desorbent consumption will be equally large.

An operation point was selected in the separation region (black dot in Figures 5 and 6), at $323 \mathrm{~K}$. The operating conditions of these points are presented in Table 3. The concentration profiles along the unit for the chosen operation point are presented in Figure 9, for propane as desorbent and in Figure 10, for $n$-butane as desorbent. The performance parameters of the unit, i.e., purity (Pur) of the streams, and recovery (Rec), are all $100 \%$. The desorbent consumption (DC) is $0,803 \mathrm{~m}^{3}$ of propane / $\mathrm{kg}$ of ethylene in the extract, and $0,798 \mathrm{~m}^{3}$ of $n$-butane $/ \mathrm{kg}$ of ethylene in the extract. Productivity (Prod) of ethylene is $3.64 \mathrm{~mol} \cdot \mathrm{kg}^{(-1)} \cdot \mathrm{h}^{(-1)}$, using propane as desorbent. On the other hand, when $n$-butane is used as desorbent, the calculated productivity of ethylene is 0.20 mol. $\mathrm{kg}^{(-1)} \cdot \mathrm{h}^{(-1)}$ As it can be seen, at these operating conditions, a large productivity may potentially be obtained for ethane/ethylene separation by SMB using $13 \mathrm{X}$ as adsorbent and propane as desorbent. As expected from the separation regions, the productivity when $n$-butane is used as desorbent is much lower.

For these operating points, if we consider a feed flow rate of $1.35 \mathrm{~m}^{3} / \mathrm{s}$, we need columns with $7.71 \mathrm{~m}^{3}$, when using propane as desorbent, and columns with $140.30 \mathrm{~m}^{3}$, when using $n$-butane as desorbent. For propane as desorbent the extract flow rate would be $1.77 \mathrm{~m}^{3} / \mathrm{s}$, the raffinate flow rate $1.83 \mathrm{~m}^{3} / \mathrm{s}$, and the desorbent flow rate $2.25 \mathrm{~m}^{3} / \mathrm{s}$. For $n$-butane as desorbent the extract flow rate would be $2.03 \mathrm{~m}^{3} / \mathrm{s}$, the raffinate flow rate $1.88 \mathrm{~m}^{3} / \mathrm{s}$, and the desorbent flow rate $2.56 \mathrm{~m}^{3} / \mathrm{s}$. 


\section{Conclusions}

In this paper we present a multiscale in silico strategy to design an SMB separation unit that combines molecular simulation with process modelling, and applied it to the challenging separation of ethane and ethylene using zeolite $13 \mathrm{X}$. The molecular model was validated first by comparing simulated single-component adsorption isotherms for ethane and ethylene on $13 \mathrm{X}$ with experimental data from several literature sources, and subsequently by comparing binary Monte Carlo simulations to estimates from the extended Toth model based on experimental single-component data. In all cases studied, there was very good agreement between simulation and experiment, giving us confidence to use our model as an adsorption prediction tool.

The results from molecular simulation were then directly used as input to the process simulation of an SMB unit to accomplish the separation of ethane and ethylene. Two candidate desorbents were evaluated, namely propane and $n$-butane. Overall, propane was found to be the most advantageous of the two candidates for this particular separation. Our results thus show that the complete separation of an ethane/ethylene mixture is feasible by SMB with a large productivity, using $13 \mathrm{X}$ as adsorbent and propane as desorbent. At this stage, we have not attempted to optimize the SMB unit, but it is likely that doing so will lead to even better separation performance.

The strategy presented here gives a good understanding on how molecular simulations can be coupled with a model for industrial applications. The results obtained from well established techniques provide a solid tool for an integrated approach from the molecular scale to process design. The choice of a good system sorbent/desorbent can be made more efficient by applying simulation techniques, provided there is an adequate combination of knowledge of these two scientific fields: molecules and processes. 


\section{Nomenclature}

$b \quad$ Affinity constant that depends on the temperature.

$D_{a x} \quad$ Axial dispersion.

$\Delta H \quad$ Heat of adsorption.

$k_{s} \quad$ Intraparticle mass transfer coefficient in the LDF model.

$k_{1,2} \quad$ Constants related to the bonded interactions: bond stretching and bond bending, respectively.

$q \quad$ In Table S1, refers to the partial charges of the cations and framework atoms.

$q_{i} \quad$ Adsorbed phase concentration.

$q_{\max } \quad$ Maximum adsorbed phase concentration.

$r \quad$ Bond length.

$r_{\text {cut }} \quad$ Cut-off radius.

$P, P_{i} \quad$ Pressure, partial pressure of component $i$.

T Absolute temperature.

$t_{i} \quad$ System heterogeneity parameter

$t^{*} \quad$ Switching time.

$u_{s} \quad$ Solid velocity

$U_{(r) \quad \text { Van der Waals potential energy }}$

$V \quad$ Volume.

Greek letters

$\varepsilon \quad$ Characteristic energy in pair potential.

$\varepsilon_{b} \quad$ Particle porosity.

$\gamma \quad$ The ratio between the fluid velocity, $v_{j}$, in the respective section and the
solid velocity, $u_{s}$, where $j$ is the SMB section. 


1
2
3
4
5
6
7
8
9
10
11
12
13
14
15
16
17
18
19
20
21
22
23
24
25
26
27
28
29
30
31
32
33
34
35
36
37
38
39
40
41
42
43
44
45
46
47
48
49
50
51
52
53
54
55
56
57
58
60

$\begin{array}{ll}\phi & \text { Torsion angle. } \\ v_{j} & \text { Fluid velocity. } \\ \eta & \text { Constants related to torsional configurations. } \\ \mu & \text { Chemical potential. } \\ \rho & \text { Particle density. } \\ \theta & \text { Bending angle. } \\ \sigma & \text { Characteristic distance in pair potential. }\end{array}$

19

20

22

23

25

26

27

29

30

32

33

34

35

37

38

39

40

41

42

44

45

46

47

48

49

50

52

53

54

55

56

57

58

59

60 


\section{Acknowledgements}

MAG thanks financial support from Fundação para a Ciência e a Tecnologia (FCT) under the post-doctoral grant SFRH-BPD-47432-2008. VMS acknowledges a scholarship from project PTDC-EQU-ERQ-104413-2008. This work is partially supported by projects PTDC-EQU-ERQ-104413-2008 and PEst-C/EQB/LA0020/2011, financed by FEDER through COMPETE - Programa Operacional Factores de Competitividade and by FCT - Fundação para a Ciência e a Tecnologia.

\section{Literature Cited}

Azevedo, D. C. S.; Rodrigues, A. E. "Design of a Simulated Moving Bed in the Presence of Mass Transfer Resistance,” AIChE Journal. 45, 956-966, (1999).

Calero, S.; Dubbeldam, D.; Krishna, R.; Smit, B.; Vlugt, T. J. H.; Denayer, J. F. M.; Martens, J. A.; Maesen, T. L. M. "Understanding the Role of Sodium During Adsorption: A Force Field for Alkanes in sodium-Exchanged Faujasites," J. Am. Chem. Soc., 126, 11377-11386 (2004).

Cheng, L. S. and S. T. Wilson, "Process for separating propylene from propane," US Patent 6,293,999 (2001).

Cruz, P.; Santos, J. C.; Magalhães, F. D.; Mendes, A. "Simulation of Separation Processes Using Finite Volume Method," Computers \& Chemical Engineering, 30, 83-98, (2005).

Da Silva, F.A.; Rodrigues, A. E. "Adsorption Equilibria and Kinetics for Propylene and Propane Over 13X and 4A Zeolite Pellets,” Ind. Eng. Chem. Res., 38, 2434-2438 (1999). 
Danner, R. P.; Choi, E. C. F. "Mixture Adsorption Equilibria of Ethane and Ethylene on 13X Molecular Sieves,” Ind. Eng. Chem. Fundam. 17, 248-253 (1978).

Dubbeldam, D.; Calero, S.; Vlugt, T. J. H.; Krishna, R.; Maesen, T. L. M.; Smit, B. "United Atom Force Field for Alkanes in Nanoporous Materials," J. Phys. Chem. B. 108, 12301-12313, (2004).

Dunne, J. A.; Rao, M.; Sircar, S.; Gorte, R. J.; Myers, A. L. "Calorimetric Heats of Adsorption and Adsorption Isotherms. 2. O2, N2, Ar, CO2, CH4, C2H6, and SF6 on NaX, H-ZSM-5, and Na-ZSM-5 Zeolites,” Langmuir, 12, 5896-5904 (1996).

Frenkel, D.; Smit, B. “Understanding Molecular Simulations: From Algorithms to Applications," 2nd ed.; Academic Press: San Diego, (2002).

Gleich, W. A. "C2-Splitter Operation with Side Draw Removal of Water to Prevent Hydrate Formation”. US Patent no. 3921411 (1975).

Granato, M. A.; Lamia, N.; Vlugt, T. J. H.; Rodrigues, A. E. "Adsorption Equilibrium of Isobutane and 1-Butene in Zeolite 13X by Molecular Simulation,” Ind. Eng. Chem. Res. 47, 6166-6174, (2008).

Granato, M. A.; Vlugt, T. J. H.; Rodrigues, A. E. "Molecular Simulation of Propane-Propylene Binary Adsorption Equilibrium in Zeolite 13X," Ind. Eng. Chem. Res. 46, 7239-7245, (2007).

Granato, Miguel A., Vlugt, Thijs J. H., Rodrigues, Alírio E. "Potential Desorbents for Propane/Propylene Separation by Gas Phase Simulated Moving Bed: A Molecular Simulation Study,” Ind. Eng. Chem. Res., 49, 5826-5833 (2010). 
Kaul, B. K. "A modern version of volumetric apparatus for measuring gas-solid equilibrium data". Ind. Eng. Chem. Res. 26, 928-983 (1987).

Kirk-Othmer, "Encyclopedia of Chemical Technology” Wiley: New York, U.S.A. 1991.

Lamia, N.; Granato, M. A.; Sá Gomes. P.; Grande, C. A.; Wolff, L.; Leflaive. P.; Leinekugel-Le-Cocq, D.; Rodrigues, A. E. "Propane/Propylene Separation by Simulated Moving Bed II. Measurement and Prediction of Binary Adsorption Equilibria of Propane, Propylene, Isobutane, and 1-Butene on 13X Zeolite,” Separation Science and Technology, 44, 1485-1509 (2009).

Leão, C. P.; Rodrigues, A. E. “Transient and Steady-State Models for Simulated Moving Bed Processes: Numerical Solutions," Computers \& Chemical Engineering, 28 (9), 1725-1741 (2004).

Martin, M. G.; Siepmann, J. I. “Transferable Potentials for Phase Equilibria - 1: United-Atom Description of n-Alkanes," J. Phys. Chem. B, 102, 2569-2577, (1998).

Mazzotti, M.; Baciocchi, R.; Storti, G.; Morbidelli, M. "Vapor-Phase SMB Adsorptive Separation of Linear/Nonlinear Paraffins," Ind. Eng. Chem. Res., 35, 2313-2321 (1996).

Minceva, M.; Pais, L. S.; Rodrigues, A. E. "Cyclic Steady State of Simulated Moving Bed Processes for Enantiomers Separation," Chemical Engineering and Processing, 42, 93-104 (2003).

Rao, D. P.; Sivakumar, S. V.; Mandal, S.; Kota, S.; Ramaprasad, B.S.G. "Novel simulated moving-bed adsorber for the fractionation of gas mixtures," $J$. Chromatogr. A., 1069, 141-151, (2005). 
Rege, S. U.; Padin, J.; Yang, R. T. “Olefin/Paraffin Separations by Adsorption: $\pi$ Complexation vs. Kinetic Separation," AIChE Journal, 44, 799-809 (1998).

Rodrigues, A. E.; Lamia, N.; Grande, C.; Wolff, L.; Leflaive, P.; Leinekugel-leCocq, D. "Procédé de Séparation du Propylène en Mélange avec du Propane par Adsorption en Lit Mobile Simulé en Phase Gaz ou Liquide Utilisant une Zéolithe de type Faujasite 13X comme Solide Adsorbant". FR. Patent no. 2903981A1 and INT. Patent WO/2008/012410A1. (2006). Also: US. Patent no. 20100069696. (2010).

Sá Gomes, P.; Minceva, M.; Rodrigues, A. E. "Operation of an Industrial SMB Unit for p-xylene Separation Accounting for Adsorbent Ageing Problems," Separation Science and Technology, 43, 1974-2002 (2008).

Sá Gomes, P.; Lamia, N.; Rodrigues, A. E. "Design of a gas-phase simulated moving bed for propane/propylene separation" Chemical Engineering Science, 64, 1336-1357 (2009).

Smit, B.; Krishna, R. "Monte Carlo Simulations in Zeolites," Curr. Opin. Solid State Mater. Sci., 5, 455-461, (2001).

Tarek, M.; Kahn, R.; de Lara, E. C. "Modelization of Experimental Isotherms of n-Alkanes in NaX Zeolite," Zeolites, 15, 67-72, (1995).

Ungerer, P.; Beauvais, C.; Delhommelle, J.; Boutin, A.; Rousseau, B.; Fuchs. A. H. "Optimization of the Anisotropic United Atoms Intermolecular Potential for $n$ Alkanes," J. Chem. Phys., 112, 5499-5510, (2000).

Valenzuela, D. P.; Myers, A. L. “Adsorption Equilibrium Data Handbook, p. 8990. Prentice-Hall, Engelwood Cliffs, N.J. (1989). 
Vlugt, T. J. H.; Krishna R.; Smit, B. Molecular Simulations of Adsorption Isotherms for Linear and Branched Alkanes and Their Mixtures in Silicalite. $J$. Phys. Chem. B. 103, 1102-1118, (1999).

Vlugt, T. J. H.; Schenk M: Influence of Framework Flexibility on the Adsorption Properties of Hydrocarbons in the Zeolite Silicalite. J. Phys. Chem. B., 106, 1275712763, (2002). 
1

2

3

4

5

6

7

8

9

10

11

12

13

14

15

16

17

18

19

20

21

22

23

24

25

26

27

28

29

30

31

32

33

34

35

36

37

38

39

40

41

42

43

44

45

46

47

48

49

50

51

52

53

54

55

56

57

58

59

60

Table 1 - Parameters of the Toth Equation.

\begin{tabular}{ccccc}
\hline Parameter & Ethane & Ethylene & Propane $^{a}$ & n-Butane \\
\hline$q_{s}[\mathrm{~mol} / \mathrm{kg}]$ & 2.21 & 2.72 & 2.68 & 1.57 \\
\hline$b_{0}\left[\mathrm{kPa}^{-1} 1\right]$ & $5.22 \times 10^{-6}$ & $1.13 \times 10^{-7}$ & $3.50 \times 10^{-7}$ & $1.37 \times 10^{-6}$ \\
\hline$-\Delta H[\mathrm{~kJ} / \mathrm{mol})$ & 21.4 & 36.3 & 35.8 & 41.2 \\
\hline$t[-]$ & 1.75 & 0.97 & 0.58 & 0.94
\end{tabular}

${ }^{a}$ Data from da Silva (1999) ${ }^{25}$.

${ }^{b}$ Data from Tarek et al (1995) ${ }^{26}$. 
Table 2 - SMB Model Parameters.

\begin{tabular}{|c|c|c|c|}
\hline Parameter & \multicolumn{2}{|l|}{ Value } & Units \\
\hline$D_{a x}$ & \multicolumn{2}{|l|}{$3.76 \times 10^{-4}$} & $\mathrm{~m}^{2} / \mathrm{s}$ \\
\hline$\varepsilon_{b}$ & \multicolumn{2}{|l|}{0.4} & - \\
\hline$\rho_{p}$ & \multicolumn{2}{|l|}{1357} & $\mathrm{~kg} / \mathrm{m}^{3}$ \\
\hline$k_{s, i}$ & \multicolumn{2}{|l|}{1} & $\mathrm{~s}^{-1}$ \\
\hline $\mathrm{T}$ & \multicolumn{2}{|l|}{323} & $\mathrm{~K}$ \\
\hline $\mathrm{P}$ & \multicolumn{2}{|l|}{110} & $\mathrm{kPa}$ \\
\hline \multirow[t]{2}{*}{$t^{*}$} & \multicolumn{2}{|l|}{76.5} & $\mathrm{~s}$ \\
\hline & Propane & $n$-Butane & \\
\hline$\gamma_{I}$ & 100 & 150 & - \\
\hline$\gamma_{I V}$ & 0.05 & 0.01 & - \\
\hline \multicolumn{3}{|c|}{ Feed Composition (molar fraction) } & Units \\
\hline Ethylene & 0.8 & & - \\
\hline Ethane & 0.2 & & - \\
\hline Configuration & $2-2-2-2$ & & - \\
\hline
\end{tabular}


1

2

3

4

5

6

7

8

9

10

11

12

13

14

15

16

17

18

19

20

21

22

23

24

25

26

27

28

29

30

31

32

33

34

35

36

37

38

39

40

41

42

43

44

45

46

47

48

49

50

51

52

53

54

55

56

57

58

59

60

Table 3 - Operating Conditions of the Selected Point for the unit using Propane and n-Butane as desorbents.

\begin{tabular}{cccc}
\hline Parameter & Propane & n-Butane & Units \\
\hline$t^{*}$ & 76.5 & 76.5 & $\mathrm{~s}$ \\
$\gamma_{I}$ & 80 & 4 & - \\
$\gamma_{I I}$ & 21 & 0.85 & - \\
$\gamma_{I I}$ & 66 & 2.95 & - \\
$\gamma_{I V}$ & 5 & 0.02 & - \\
\hline
\end{tabular}

John Wiley \& Sons 


\section{List of Figures}

Figure 1 - Isotherms on $13 \mathrm{X}$ zeolite at 393 and $423 \mathrm{~K}$ : (a) Ethane; (b) Ethylene. Open symbols are experimental data from Kaul, (1987). Closed symbols are our simulations, which account for the presence of $20 \%$ of binder in the experimental sample.

Figure 2 - Isotherms of Ethane on $13 \mathrm{X}$ zeolite at $305 \mathrm{~K}$. Open symbols are experimental data from Dunne et al., (1996). Closed symbols are our simulations.

Figure 3 - Binary adsorption equilibrium for ethane/ethylene at a total pressure of 137.8 $\mathrm{kPa}$, calculated from the extended Toth model with experimental single component data from Danner and Choi (1978), predicted from CBMC simulations, and compared with experimental binary adsorption data form Kaul (1987).

Figure 4a - Binary adsorption equilibrium at $373 \mathrm{~K}$ and total pressure of $110 \mathrm{kPa}$. ${ }^{(a, b)}$ Experimental single component data used in the extended Toth model were taken from Danner and Choi (1978) for ethane and ethylene, and from Tarek et al. (1995) for n-butane.

Figure 4b - Binary adsorption equilibrium at $373 \mathrm{~K}$ and total pressure of $110 \mathrm{kPa}$. ${ }^{(a, b)}$ Experimental single component data used in the extended Toth model were taken from Danner and Choi (1978) for ethane and ethylene, and from Da Silva and Rodrigues (1999) for propane.

Figure 5 - Separation regions obtained by simulation using propane as desorbent at four different temperatures, and at $\mathrm{P}=110 \mathrm{kPa}$. The selected operating point is shown as a black circle.

Figure 6 - Separation regions obtained by simulation using n-butane as desorbent at four different temperatures, and at $\mathrm{P}=110 \mathrm{kPa}$. The selected operating point is shown as a black circle.

Figure 7 - Single component isotherms at different temperatures.

Figure 8 - Binary component equilibrium diagrams at different temperatures.

Figure 9 - Concentration profile along the unit for the selected operating point using propane as desorbent.

Figure 10 - Concentration profile along the unit for the selected operating point using n-butane as desorbent.

Figure S1 - Isotherms of propane and n-butane. Taken from Granato et al. $(2007,2010)$. 


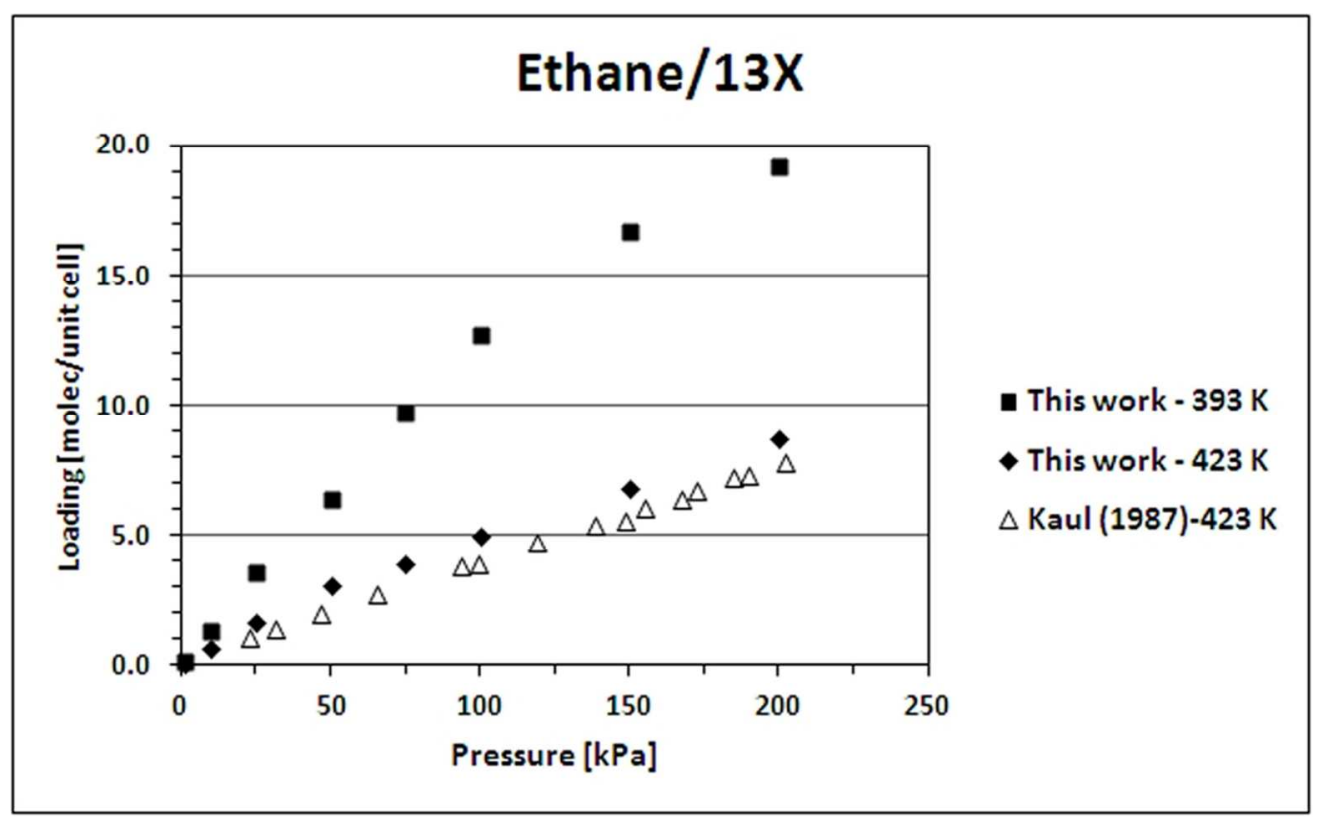

$86 \times 53 \mathrm{~mm}(300 \times 300$ DPI $)$ 
Figure 1 - Isotherms on $13 \mathrm{X}$ zeolite at 393 and $423 \mathrm{~K}$ : (a) Ethane; (b) Ethylene. Open symbols are experimental data from Kaul, (1987). Closed symbols are our simulations, which account for the presence of $20 \%$ of binder in the experimental sample.

$86 \times 53 \mathrm{~mm}(300 \times 300$ DPI $)$ 
Figure 2 - Isotherms of Ethane on $13 \mathrm{X}$ zeolite at $305 \mathrm{~K}$. Open symbols are experimental data from Dunne et al., (1996). Closed symbols are our simulations. $86 \times 53 \mathrm{~mm}(300 \times 300$ DPI $)$ 
Figure 3 - Binary adsorption equilibrium for ethane/ethylene at a total pressure of $137.8 \mathrm{kPa}$, calculated from the extended Toth model with experimental single component data from Danner and Choi (1978), predicted from CBMC simulations, and compared with experimental binary adsorption data form Kaul (1987).

$140 \times 84 \mathrm{~mm}(300 \times 300$ DPI $)$ 


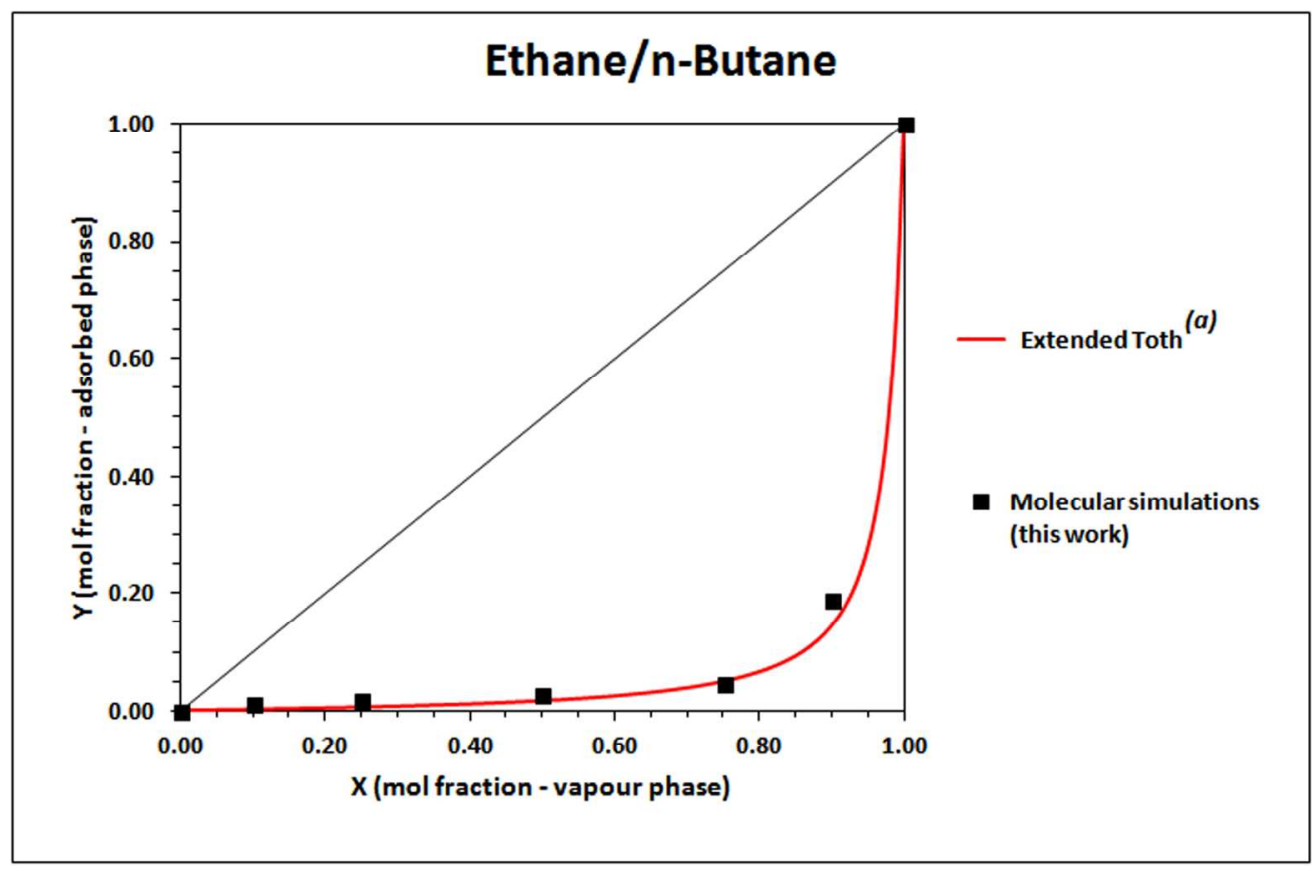

$140 \times 92 \mathrm{~mm}(300 \times 300 \mathrm{DPI})$ 
Figure $4 \mathrm{a}$ - Binary adsorption equilibrium at $373 \mathrm{~K}$ and total pressure of $110 \mathrm{kPa}$. (a,b)Experimental single component data used in the extended Toth model were taken from Danner and Choi (1978) for ethane and ethylene, and from Tarek et al. (1995) for n-butane. 


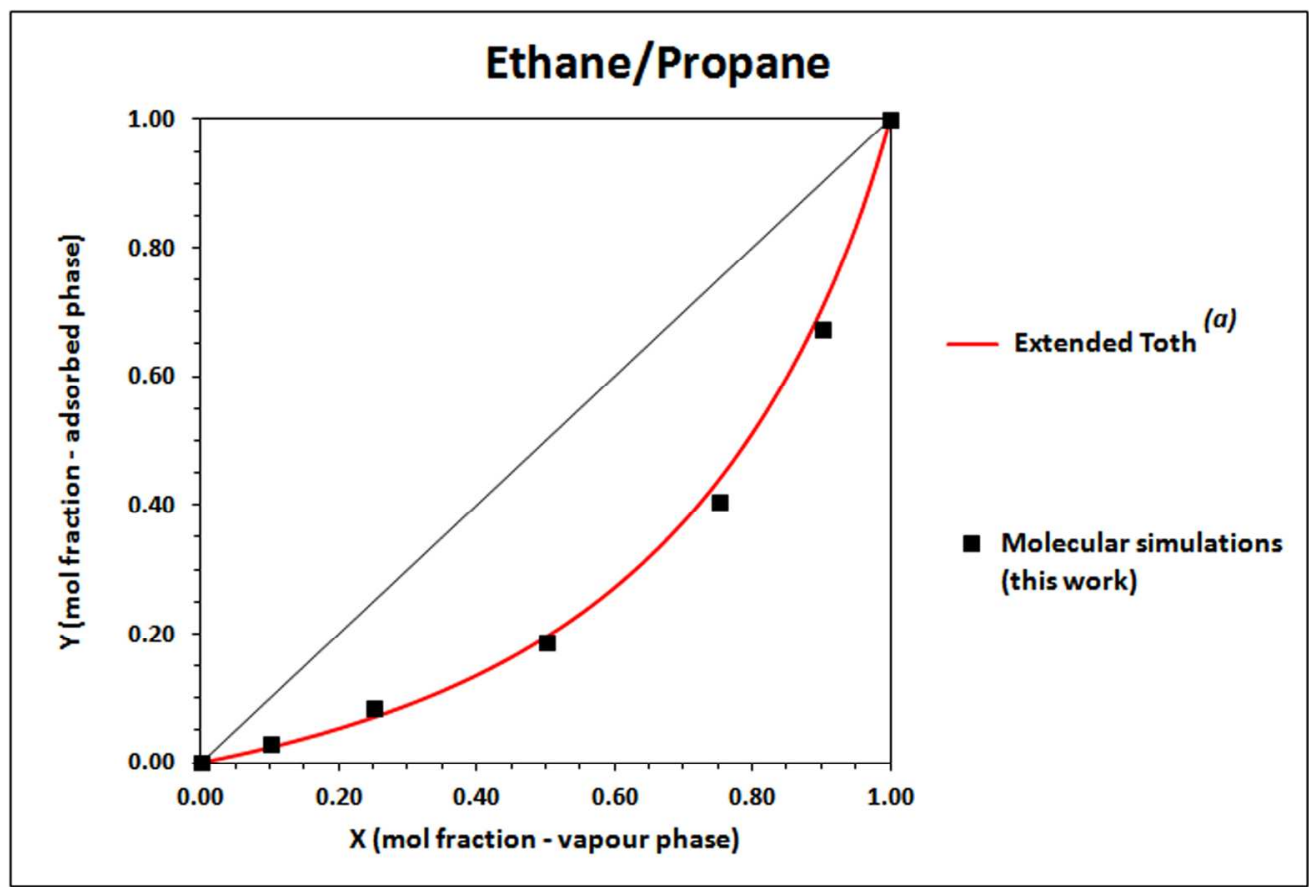

$140 \times 94 \mathrm{~mm}(300 \times 300$ DPI $)$ 
Figure $4 \mathrm{~b}$ - Binary adsorption equilibrium at $373 \mathrm{~K}$ and total pressure of $110 \mathrm{kPa}$. (a,b)Experimental single component data used in the extended Toth model were taken from Danner and Choi (1978) for ethane and ethylene, and from Da Silva and Rodrigues (1999) for propane.

\section{$140 \times 94 \mathrm{~mm}(300 \times 300$ DPI $)$}


Figure 5 - Separation regions obtained by simulation using propane as desorbent at four different temperatures, and at $\mathrm{P}=110 \mathrm{kPa}$. The selected operating point is shown as a black circle.

$$
110 \times 87 \mathrm{~mm}(300 \times 300 \text { DPI })
$$


Figure 6 - Separation regions obtained by simulation using $n$-butane as desorbent at four different temperatures, and at $\mathrm{P}=110 \mathrm{kPa}$. The selected operating point is shown as a black circle. $110 \times 87 \mathrm{~mm}(300 \times 300 \mathrm{DPI})$ 


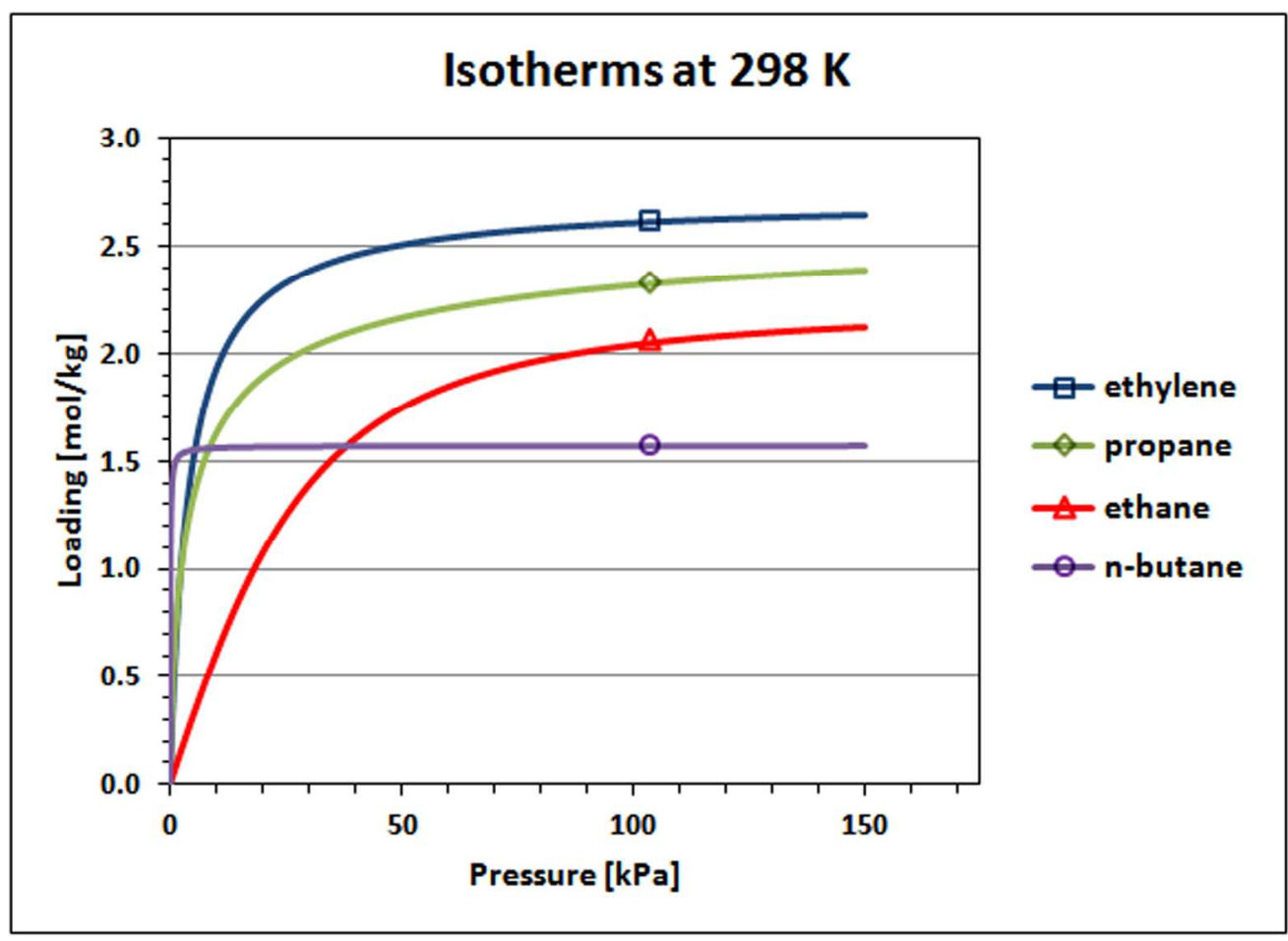

$140 \times 101 \mathrm{~mm}(300 \times 300$ DPI $)$ 


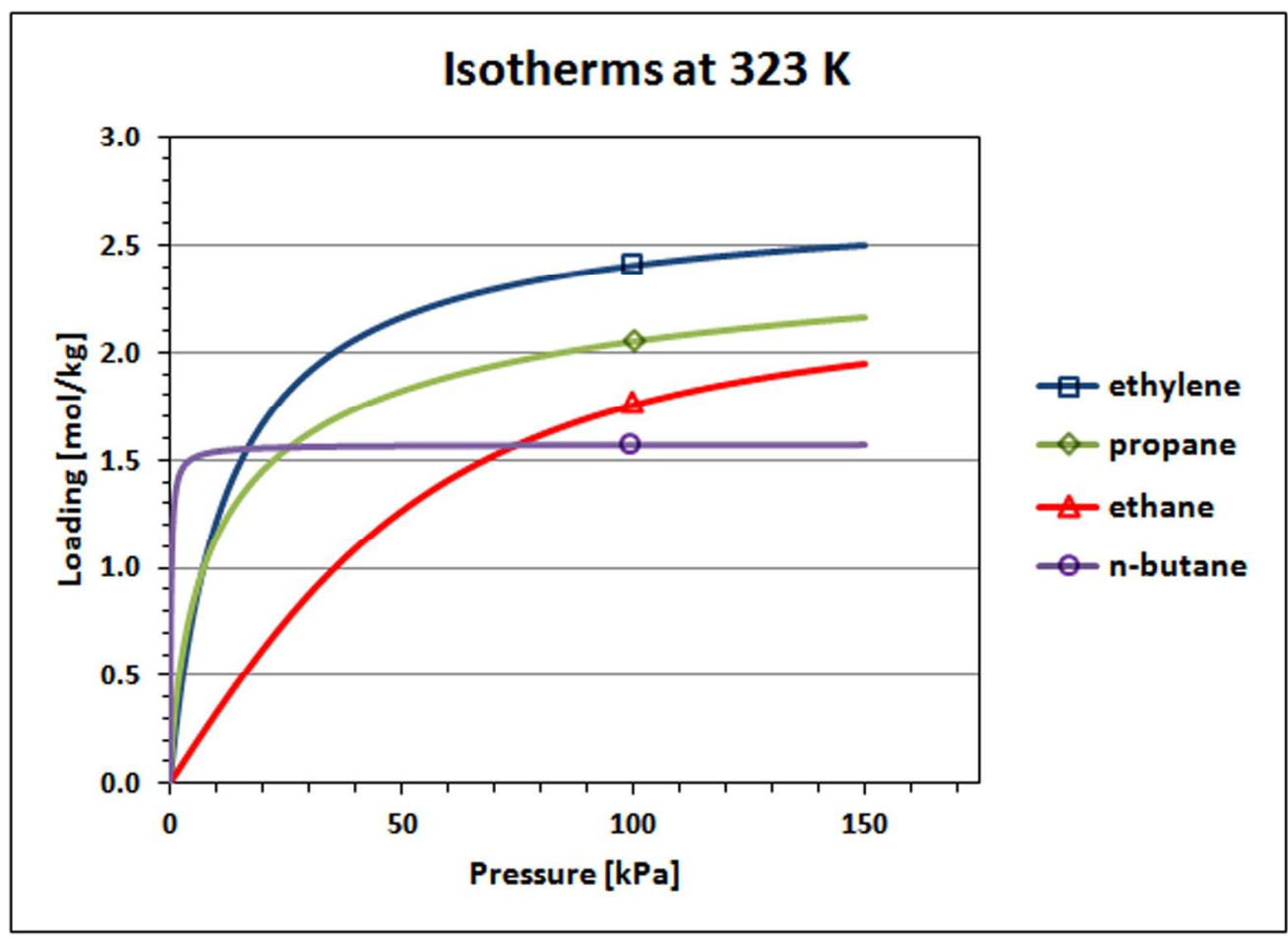

$140 \times 101 \mathrm{~mm}(300 \times 300 \mathrm{DPI})$

John Wiley \& Sons 


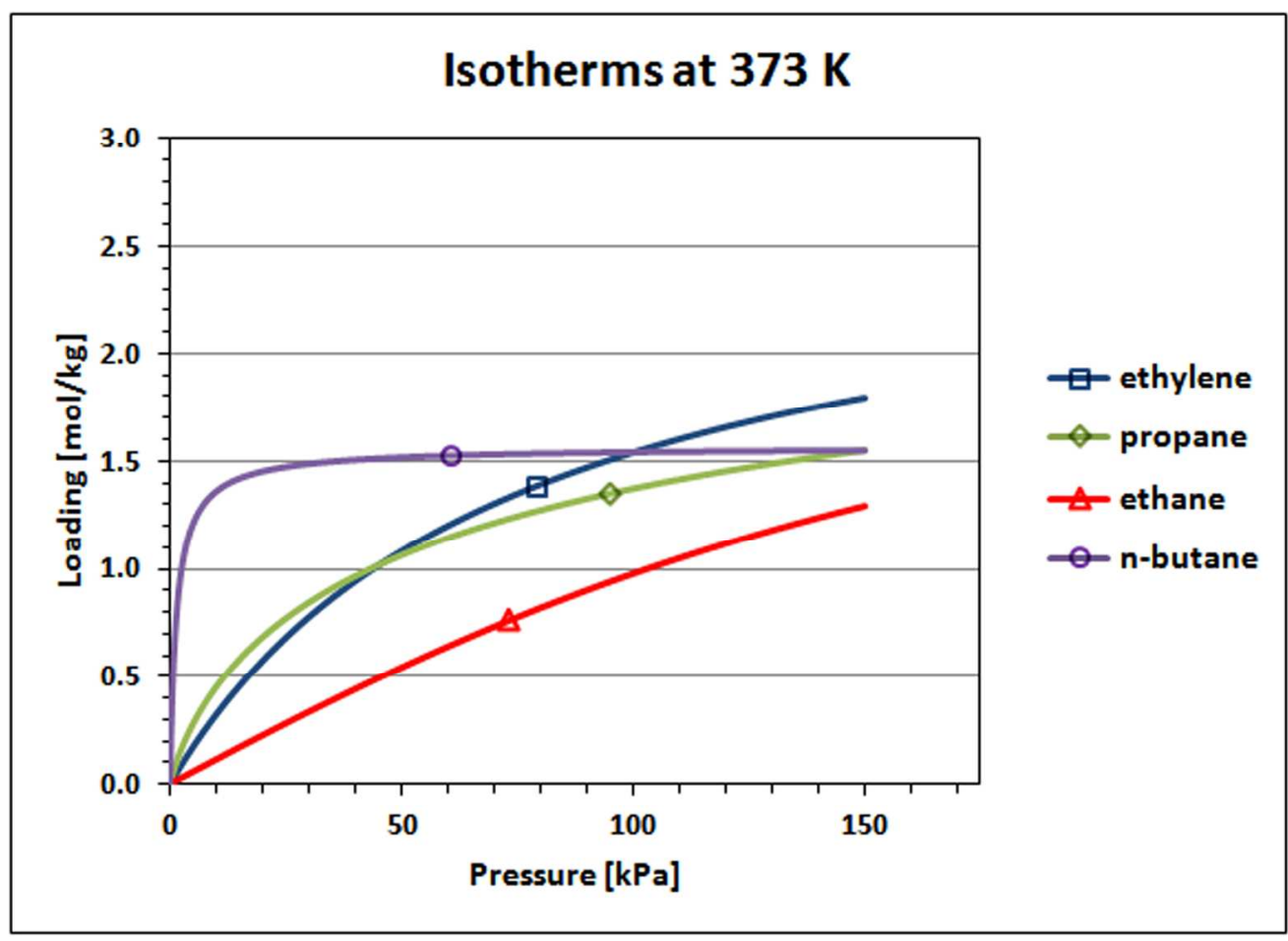

$140 \times 101 \mathrm{~mm}(300 \times 300 \mathrm{DPI})$ 


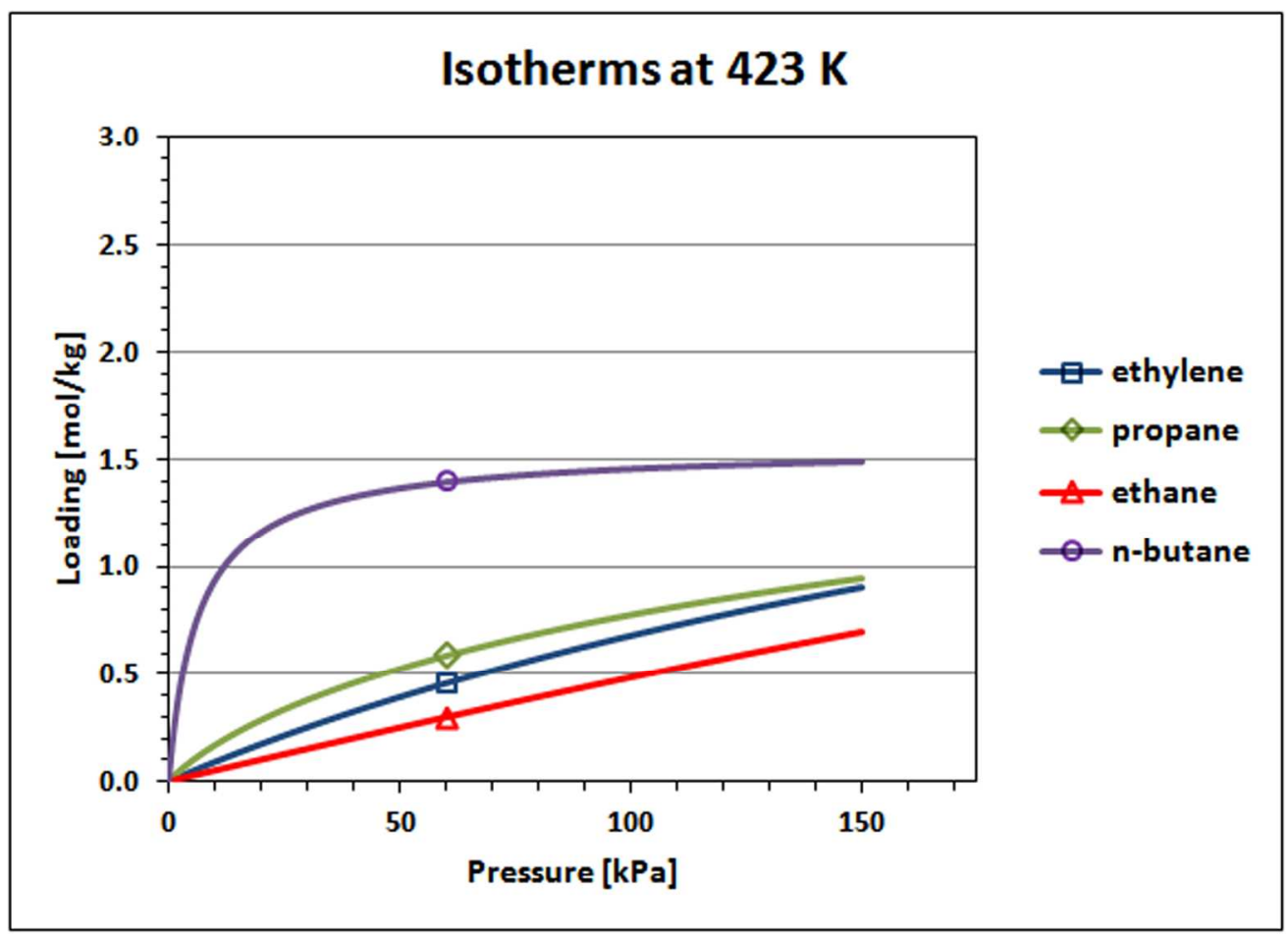

Figure 7 - Single component isotherms at different temperatures. $140 \times 101 \mathrm{~mm}(300 \times 300$ DPI $)$ 


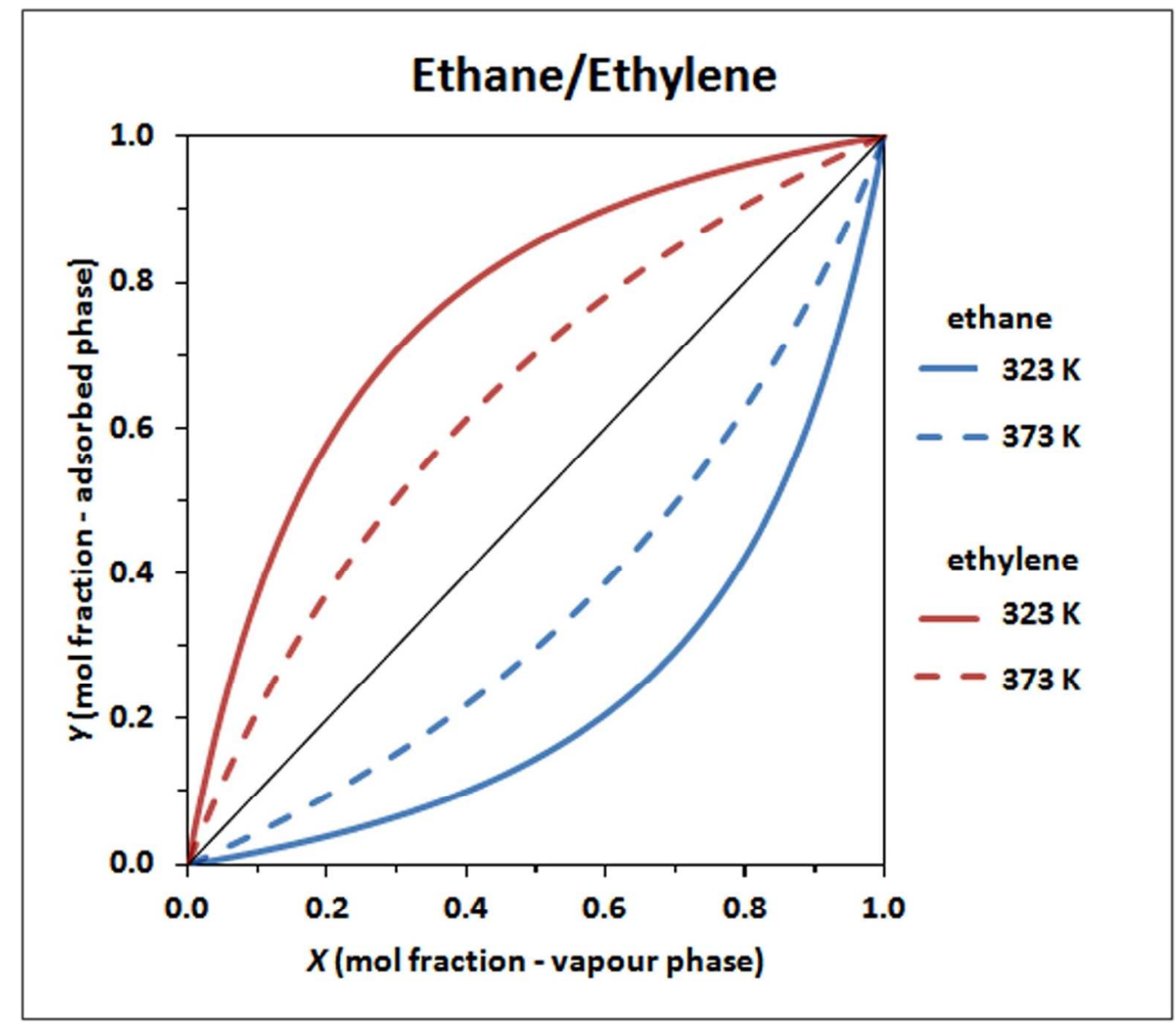

Figure 8 - Binary component equilibrium diagrams at different temperatures. $122 \times 107 \mathrm{~mm}(300 \times 300 \mathrm{DPI})$ 


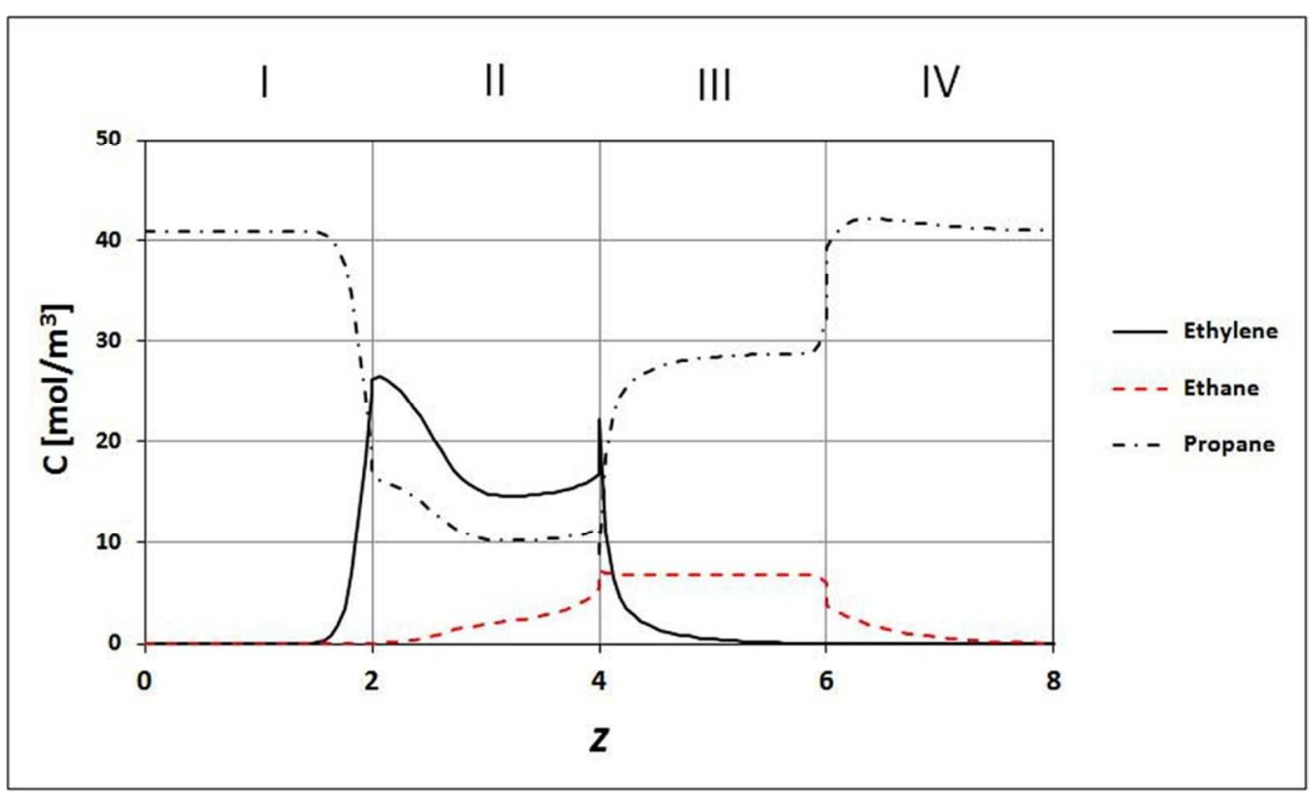

Figure 9 - Concentration profile along the unit for the selected operating point using propane as desorbent. $83 \times 49 \mathrm{~mm}(300 \times 300 \mathrm{DPI})$ 
1

2

3

4

5

6

7

8

9

10

11

12

13

14

15

16

17

18

19

20

21

22

23

24

25

26

27

28

29

30

31

32

33

34

35

36

37

38

39

40

41

42

43

44

45

46

47

48

49

50

51

52

53

54

55

56

57

58

59

60

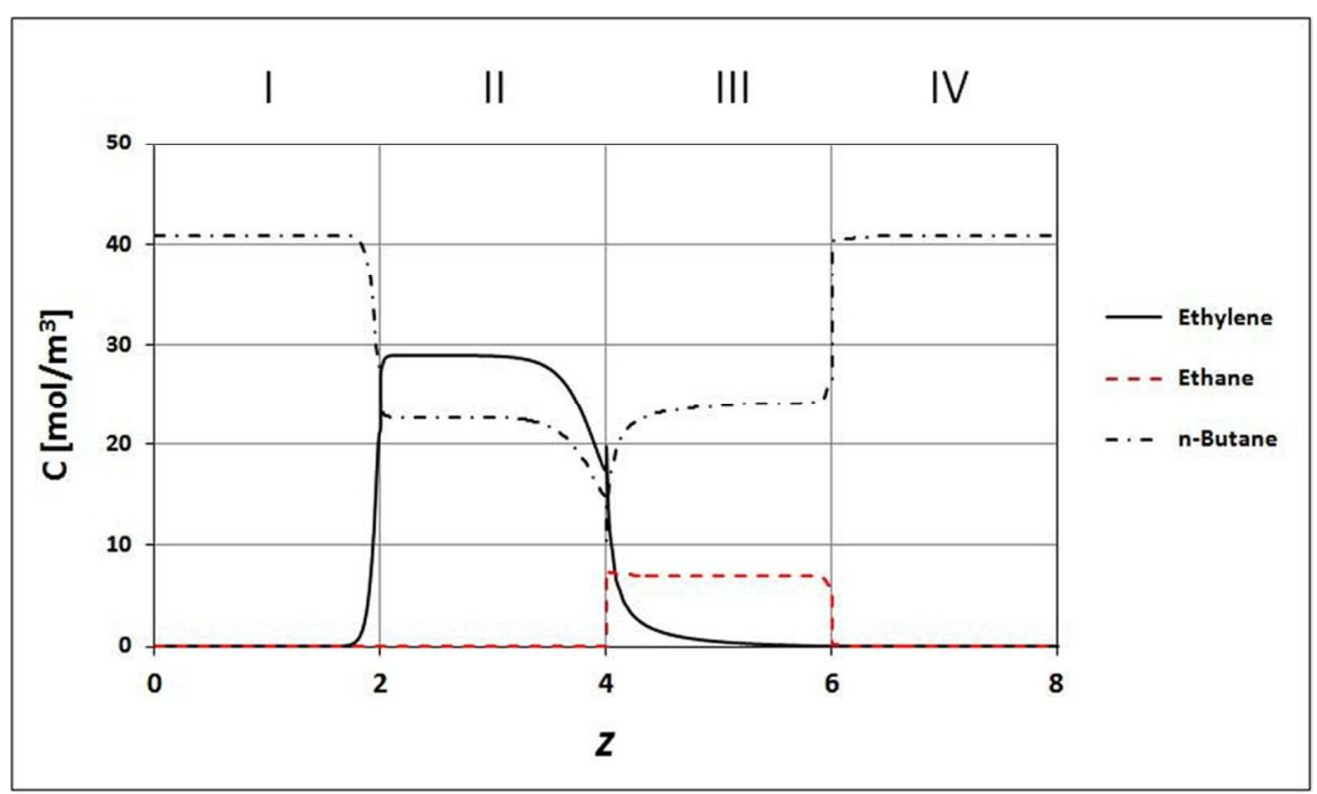

Figure 10 - Concentration profile along the unit for the selected operating point using $\mathrm{n}$ butane as desorbent. $83 \times 49 \mathrm{~mm}(300 \times 300$ DPI $)$ 


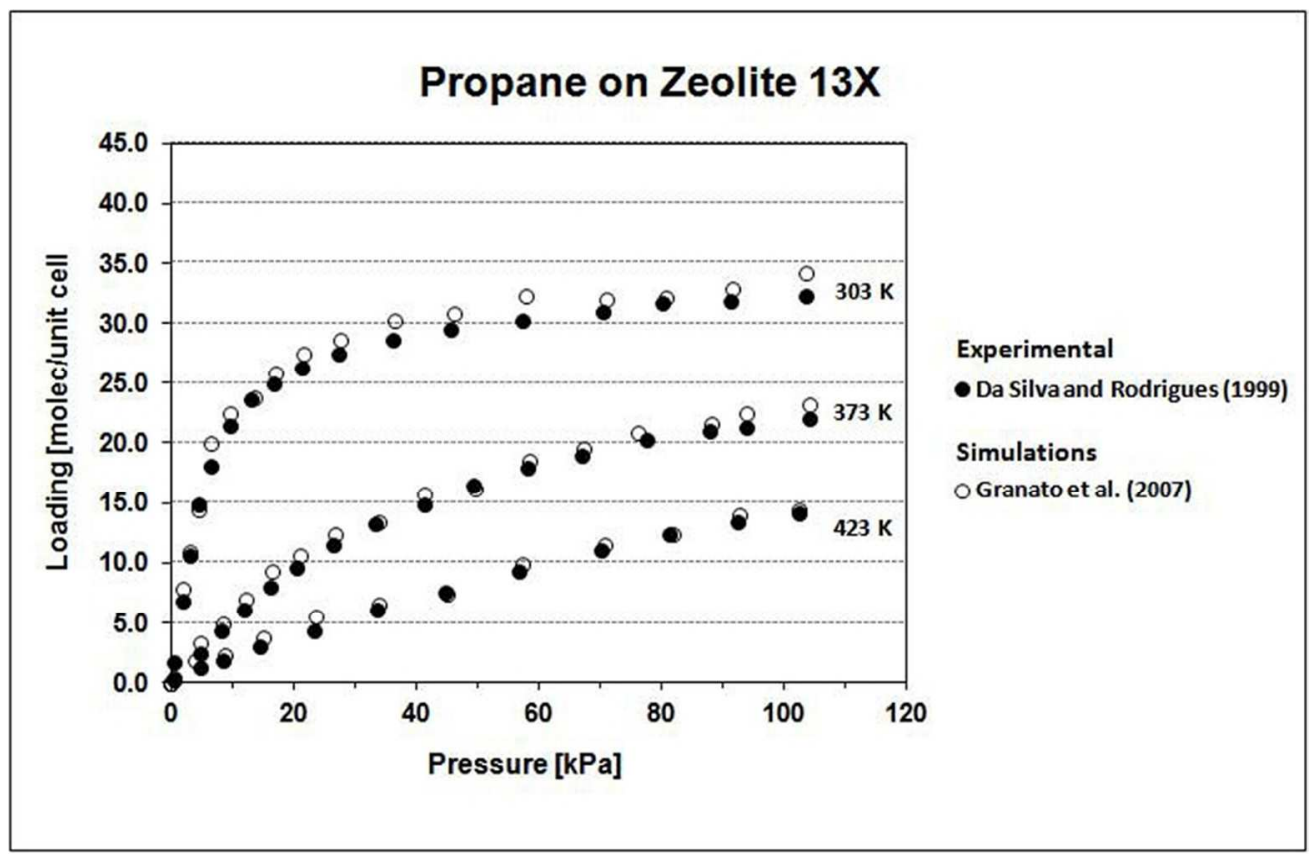

$90 \times 58 \mathrm{~mm}(300 \times 300 \mathrm{DPI})$ 
Figure S1 - Isotherms of propane(a) and n-butane(b). Taken from Granato et al. (2007, 2010). $170 \times 110 \mathrm{~mm}(300 \times 300$ DPI) 